\title{
The Enthalpy of Solution of Low Quartz ( $\alpha$-quartz) in Aqueous Hydrofluoric Acid
}

\author{
Marthada V. Kilday and Edward J. Prosen \\ Institute for Materials Research, National Bureau of Standards, Washington, D.C. 20234
}

(November 9, 1972)

\begin{abstract}
An adiabatic solution calorimeter was used to measure the enthalpy of solution of the NBS Standard Reference Material No. 1654 ( $\alpha$-quartz or low quartz) for use as a reference standard for HF solution calorimetry. The enthalpy of solution of this material at a concentration of 5 grams in $1000 \mathrm{~cm}^{3}$ of 24.4 weight percent $\mathrm{HF}(\mathrm{aq})$ is
\end{abstract}

$$
-\Delta H_{\text {soln }}(353.15 \mathrm{~K})=2362.2 \pm 1.1 \mathrm{~J} \cdot \mathrm{g}^{-1} \text {. }
$$

This value also applies to the enthalpy of solution of pure low quartz within the uncertainty limits given. The enthalpy of solution of quartz (in $\mathrm{J} \cdot \mathrm{g}^{-1}$ ) as a function of the temperature, $T$, of reaction in 24.4 weight percent $\mathrm{HF}$ in the range 298 to $358 \mathrm{~K}$, is

$$
-\Delta H_{\text {soln }}(T)=2275.0+1.586(T-298.15) .
$$

Thus, the average $\Delta C p$ for the reaction over the range, 298 to $358 \mathrm{~K}$, is $-1.586 \pm 0.025 \mathrm{~J} \cdot \mathrm{g}^{-1} \cdot \mathrm{K}^{-1}$. As a function of the concentration of HF solution in the range, 18 to 30 weight percent,

$$
-\Delta H_{\mathrm{soln}}(353.15 \mathrm{~K})=2362.10+1.429(\mathrm{wt} \% \mathrm{HF}-24.40)+0.069(\mathrm{wt} \% \mathrm{HF}-24.40)^{2} .
$$

From measurements of the enthalpies of solution of several samples of quartz and fused silica, the enthalpy difference between low quartz and silica glass at $298.15 \mathrm{~K}$ was determined to be $162.2 \pm 4.9$ $\mathrm{J} \cdot \mathrm{g}^{-1}\left(2.330 \pm 0.070 \mathrm{kcal} \cdot \mathrm{mol}^{-1}\right)$.

Key words: Enthalpy of soln, $\mathrm{SiO}_{2}$; heat of soln, $\mathrm{SiO}_{2}(\mathrm{c})$; quartz, soln in $\mathrm{HF}(\mathrm{aq})$; reference material, soln calorimetry; $\mathrm{SiO}_{2}(\mathrm{c})$, soln in $\mathrm{HF}(\mathrm{aq})$; thermochemistry.

\section{Introduction}

The growth of HF solution calorimetry in the past few decades has produced a need for a standard reference material to assist in determining the accuracy and precision of results obtained by calorimeters measuring heats of solution in hydrofluoric acid. This acid is generally used because of its great chemical activity and ability to attack even refractory materials such as oxides and silicates. Thus, by measuring enthalpies of solution in HF of various materials, they can be related even though their properties may be very different.

The reference standards often used in other types of solution calorimetry react rapidly at room temperature and are not suitable for HF work where the reactions are usually slow, and the calorimetrist resorts to higher temperatures and very finely divided samples in order to increase the reaction rate. One of the key compounds relating many systems in this field is $\mathrm{SiO}_{2}$ (c) or quartz; therefore at the request of the U.S. Calorimetry Conference, the National Bureau of Standards has made available NBS Standard Refer- ence Material No. 1654 ( $\alpha$-quartz) for HF solution calorimetry. ${ }^{1}$

SRM No. 1654 is not intended to be used for calibrating calorimeters, as a replacement for electrical energy calibration. It is intended as a single, uniform sample for comparison of measurements by various calorimeters for establishing the adequacy of measurement techniques.

This quartz sample should prove useful in $\mathrm{HF}$ solution calorimetry because it dissolves in wellstirred 24 percent $\mathrm{HF}$ in approximately $2 \mathrm{~h}$ at $353 \mathrm{~K}$. It is of high purity; it is free from finely divided particles which may introduce surface energy effects; and it requires no special preparation nor techniques in handling.

The purpose of this paper is to describe the preparation and analysis of SRM 1654 and to describe the experimental work which resulted in the certified value for the enthalpy of solution.

\footnotetext{
${ }^{1}$ This material can be obtained through the Office of Standard Reference Materials, National Bureau of Standards, $\bar{W}_{\text {ashington, D.C. } 20234 .}$
} 
The results are also given in section 4 for some of our earlier work with samples of Norwegian and Quebec crystalline quartz and a fused silica glass. This work is not of the high precision achieved in the certification experiments, however, it does add some information about the effects of elutriation of samples and about the enthalpy difference between quartz and the glass.

There has been confusion in the use of the terms $\alpha$ - and $\beta$-quartz [1]. ${ }^{2}$ In this paper, $\alpha$-quartz refers to the low quartz (stable below $846 \mathrm{~K}$ ).

\section{The Sample}

Two pieces of natural Brazilian quartz weighing a total of approximately $4 \mathrm{~kg}$ were the starting material for SRM 1654. Surface impurities included in abrasions were removed with a carborundum saw. The surface was washed with a soap solution and then with acetone. At this point the two pieces were clear and colorless with no flaws visible.

The quartz was crushed by hand in a mortar of hardened steel. Bronze sieves separated the material into three portions: (1) passed \#100 and retained on \#200 sieve (74 to $149 \mu \mathrm{m}), 1.1 \mathrm{~kg}$; (2) passed \#200 and retained on \#400 sieve (37 to $74 \mu \mathrm{m}), 2.3 \mathrm{~kg}$; and (3) passed \#400 sieve $(<37 \mu \mathrm{m}), 0.6 \mathrm{~kg}$. Spectroscopic analysis indicated that a sample from portion (2) contained more than $0.1 \mathrm{wt}$ percent $\mathrm{Fe}$ and a trace of $\mathrm{Cu}$. The metallic impurities were removed from all three portions by solution in aqueous hydrochloric acid at approximately $320 \mathrm{~K}$ as described in the following paragraph. The three portions of different particle size were kept separate but treated alike, although only portion (2) was to be used for SRM 1654.

The quartz was contained in a $3000-\mathrm{cm}^{3}$ Pyrex glass beaker while washing with a $1: 1$ solution of concentrated hydrochloric acid in distilled water. The contents of the beaker were stirred with a polyethylene stirring rod while being heated to approximately $320 \mathrm{~K}$. The supernatant liquid was decanted and the process repeated once beyond the point where the washings gave no test for iron with $0.25 M \mathrm{~K}_{3} \mathrm{Fe}(\mathrm{CN})_{6}$ solution. Then the quartz was repeatedly washed with distilled water heated to $320 \mathrm{~K}$ until the washings gave no test for Cl- with $0.1 M \mathrm{AgNO}_{3}$ solution. The washing was continued with distilled water at room temperature to remove the finest particles from the quartz. When no suspended particles were visible in the water after the mixture remained unstirred for $l \mathrm{~h}$, the water was decanted, and the quartz was loosened to a fluffy mass before drying for 3 to $5 \mathrm{~h}$ at $448 \mathrm{~K}$. Abrasion by the quartz was apparent on the polyethylene stirring rod, but not on the glass beakers.

Spectrochemical analysis ${ }^{3}$ of the final products indicated that no detectable amount of $\mathrm{Fe}$ or $\mathrm{Cu}$ remained in the sample, and only traces $(<0.001 \mathrm{wt} \%)$ of $\mathrm{Al}$ and $\mathrm{Mg}$ were detected. Two samples (3.3 g and $1.9 \mathrm{~g}$ ) of the SRM 1654 were treated with aqueous

\footnotetext{
${ }^{2}$ Figures in brackets indicate literature references at the end of this paper.

${ }^{3}$ Performed by V. C. Stewart, Spectrochemical Analysis Section, Analytical Chemistry Division.
}

HF and evaporated to dryness several times to determine the material inert to HF. ${ }^{4}$ The amount found averaged 0.02 percent although the residues were hygroscopic and the weights varied somewhat with atmospheric humidity. No evidence of undissolved residue was ever found in the calorimetric experiments.

Examination of an x-ray diffraction pattern ${ }^{5}$ of the SRM 1654 did not indicate the presence of phases other than low quartz. The limit of detection of another form of crystalline $\mathrm{SiO}_{2}$ was estimated to be between 0.1 and 1.0 percent.

The weight loss by the SRM 1654 on drying at 538 $\mathrm{K}$ was determined to be 0.02 percent or less, and on ignition at $1550 \mathrm{~K}, 0.02$ percent. During the remaining measurements the material was stored in glass bottles in the room atmosphere in which a relative humidity of $35 \pm 10$ percent was maintained.

\section{Apparatus and Procedures}

In this paper, the 1969 atomic weights [2] were used (H, 1.0080; F, 18.9984; O, 15.9994; Si, 28.086), and 4.1840 joules $=1$ calorie. In converting to molar quantities, the samples were assumed to be pure $\mathrm{SiO}_{2}$, and the possible presence of small amounts of impurities was neglected. The following densities, in $\mathrm{g} \cdot \mathrm{cm}^{-3}$, were used to calculate buoyancy factors: quartz, 2.66; $\mathrm{SiO}_{2}$ glass, $2.20 ; 18$ percent $\mathrm{HF}, 1.063$; 24 percent $\mathrm{HF}, 1.083$; 30 percent $\mathrm{HF}, 1.101$; and air (for average conditions in our laboratory), 0.00118 .

The platinum-lined, adiabatic solution calorimeter used in this work was described in detail previously [3]. The stirrer was operated at a speed of $350 \mathrm{rpm}$, and the sample cylinder, $1.9-\mathrm{cm}^{3}$ volume, with polytetrafluoroethylene (PTFE) o-rings was used for the platinum sample holder.

The aqueous HF solutions used in the measurements were taken from stock solutions stored in $2000-\mathrm{cm}^{3}$ polyethylene bottles. The solutions were prepared by approximate volumetric dilutions of analytical reagent grade concentrated hydrofluoric acid with distilled water. Weighed aliquots of the stock solutions were analyzed by titration against standard $1 \quad N$ sodium hydroxide solution using phenolphthalein as an end-point indicator.

In each experiment the platinum sample holder containing the weighed sample was installed in the calorimeter, and the HF solution was weighed in a polyethylene bottle and then transferred to the calorimeter vessel. When the calorimeter was completely assembled the jacket was evacuated by means of an oil diffusion pump. A pressure of less than 0.1 $\mathrm{Pa}\left(1 \times 10^{-3} \mathrm{~mm} \mathrm{Hg}\right)$ was observed in approximately $2 \mathrm{~h}$. During this time the controls for the adiabatic shield were started and the calorimeter was preheated to the desired starting temperature. About $2 \mathrm{~h}$ was required for heating to $353 \mathrm{~K}$. Approximately $\mathrm{l} \mathrm{h}$ was allowed for thermal equilibration in the system before starting the temperature measurements. This 
time period was longer than that following electrical calibrations because the longer time of heating with greater voltage across the calorimeter heater resulted in lags, especially in the temperature of the jacket well and its insulation.

During the 25-min rating periods, calorimeter temperature readings were made at 5 -min intervals when the 25- $\Omega$ platinum resistance thermometer was used, and at $100-\mathrm{s}$ intervals when the quartz-oscillator thermometer was used. After the first rating period an electrical calibration of the initial system was made using $24 \mathrm{~V}$ across the $97-\Omega$ manganin heater for 10.5 min. Alternate measurements of current in the calorimeter heater and the potential across it were made at 30 -s intervals during the electrical heating using a high precision potentiometer. Details of the electrical energy measurements were described previously [3]. The time of the electrical heating was measured by an electronic counter which counted cycles of the 10$\mathrm{kHz}$ standard frequency signal available at NBS. The second rating period was started about $12 \mathrm{~min}$ after completion of the calibration heating. Following the second rating period, the sample holder was opened and the slow solution reaction began. At 298 $\mathrm{K}$, samples of the finest material $(<37 \mu \mathrm{m})$ required $6 \mathrm{~h}$ for complete reaction, SRM 1654 (37 to $74 \mu \mathrm{m})$ required $10 \mathrm{~h}$, and the coarsest material (74 to 149 $\mu \mathrm{m})$ required $16 \mathrm{~h}$. At $353 \mathrm{~K}$, these materials required 1,2 , and $4 \mathrm{~h}$ respectively. At $353 \mathrm{~K}$, SRM 1654 required for complete reaction $3 \mathrm{~h}$ in 18 percent $\mathrm{HF}$, $2 \mathrm{~h}$ in 24 percent $\mathrm{HF}$, and $1.5 \mathrm{~h}$ in 30 percent $\mathrm{HF}$. The reactions were assumed to be complete when the slopes of the time-temperature curves were approximately the same as those of the initial rating periods and when the slope did not change more than the uncertainty of the readings. The measurements for a third rating period were followed by an electrical calibration of the final system in which the same procedure was used as in the initial calibration. A fourth rating period then completed the measurements.

The slopes in the rating periods were of the order of $200 \mu \mathrm{K} \cdot \min ^{-1}$ and the uncertainty in the stirring energy was estimated to be \pm 5 percent, or less. Thus, for a reaction with a $2-\mathrm{K}$ temperature rise and requiring $2 \mathrm{~h}$ for completion, the total stirring energy would be about $24 \mathrm{mK}$ and the uncertainty in $\Delta T_{c}$, about \pm 0.06 percent. However, the experimental imprecision actually observed was about one-third of this uncertainty.

In all experiments the final solutions appeared clear with no evidence of undissolved residue. The solutions were neutralized with soda lime before disposal.

Because this calorimeter is adiabatic, the corrected temperature rise is calculated directly from the projected slopes of the rating periods (the slopes are essentially the same in all rating periods). The only corrections applied were those for the calibrations of the resistance bridge or the quartz-oscillator thermometer.

The quartz-oscillator thermometer, calibrated by comparison with the platinum resistance thermometer, was used for the temperature measurements in Expts. No. 432 through 474. In Expts. No. 479 through 502, the temperature measurements were made with the
25- $\Omega$ platinum resistance thermometer and a $\mathrm{G}-3$ resistance thermometer bridge using a nanovoltmeter as a null detector; the nanovoltmeter deflections were recorded on a strip-chart recorder.

\section{Preliminary Experiments}

The experimental results given in this section are not of the accuracy and precision achieved in the experiments in section 5. However they are useful in estimating the effects of elutriating samples, in comparing the enthalpies of solution of natural quartz from different sources, and in obtaining a value for the enthalpy difference between crystalline quartz and silica glass.

These measurements were made between January and March 1966, before our laboratories were moved to the location at Gaithersburg, Maryland. Since that time, the calorimeter has been modified in a number of ways to improve the precision and accuracy of the measurements. We estimate the experimental imprecision for these measurements to be about 0.05 to 0.1 percent as compared to 0.02 percent in the certification work. The calorimeter as described [3] included the following changes: the sample holder was redesigned; a temperature control was added to the potentiometer; bearıngs were added to the stirrer; and the temperature and humidity in the new laboratory were automatically controlled.

Three samples of $\mathrm{SiO}_{2}$ were used in the measurements described in this section: ${ }^{6}$

1. Norwegian crystalline quartz, obtained from Hammill and Gillespie, Inc., New York. Spectroscopic analysis for metallic constituents: $\mathrm{Al}$ and $\mathrm{Ti}$, 0.001-0.01 percent; Ag, B, Ca, Cu, Fe, Mg, Mn, less than 0.001 percent. (See footnote 3.)

2. Buckingham, Quebec, crystalline quartz, obtained from International Minerals and Chemical Corp., Buckingham, Quebec. Spectroscopic analysis was the same as for the Norwegian quartz. (See footnote 3.)

3. Suprasil 2, an optical-quality fused silica glass, obtained from Englehard Industries, Amersil Quartz Division, Hillside, New Jersey. Spectroscopic analysis: $\mathrm{Fe}, 0.01-0.1$ percent; Al, Ba, and $\mathrm{Mg}, 0.001-0.01$ percent; and $\mathrm{Ag}, \mathrm{Ca}, \mathrm{Cr}, \mathrm{Cu}$, and $\mathrm{Mn},<0.001$ percent (See footnote 3.)

$\mathrm{X}$-ray powder diffraction analysis of these materials indicated that the first two were crystalline low quartz, and that there was no crystalline material in the third sample. (See footnote 5.) The transmission spectra through Suprasil in the ultraviolet, visible, and infrared regions are given in figure 1 . In the infrared there are strong absorptions at $2.72 \mu \mathrm{m}$ and secondary absorption bands at 1.38 and $2.22 \mu \mathrm{m}$. According to the manufacturer's specification, the synthetic fused silica, Suprasil, has a density of $2.201 \mathrm{~g} \cdot \mathrm{cm}^{-3}$ and the annealing point is $1393 \mathrm{~K}$.

${ }^{6}$ Certain commercial products and instruments are identified in this paper in order to specify adequately the experimental procedure. In no case does such identification imply recommendation or endorsement by the National Bureau of Standards, nor does it imply that the products or equipment identified are necessarily the best available for the purpose. 

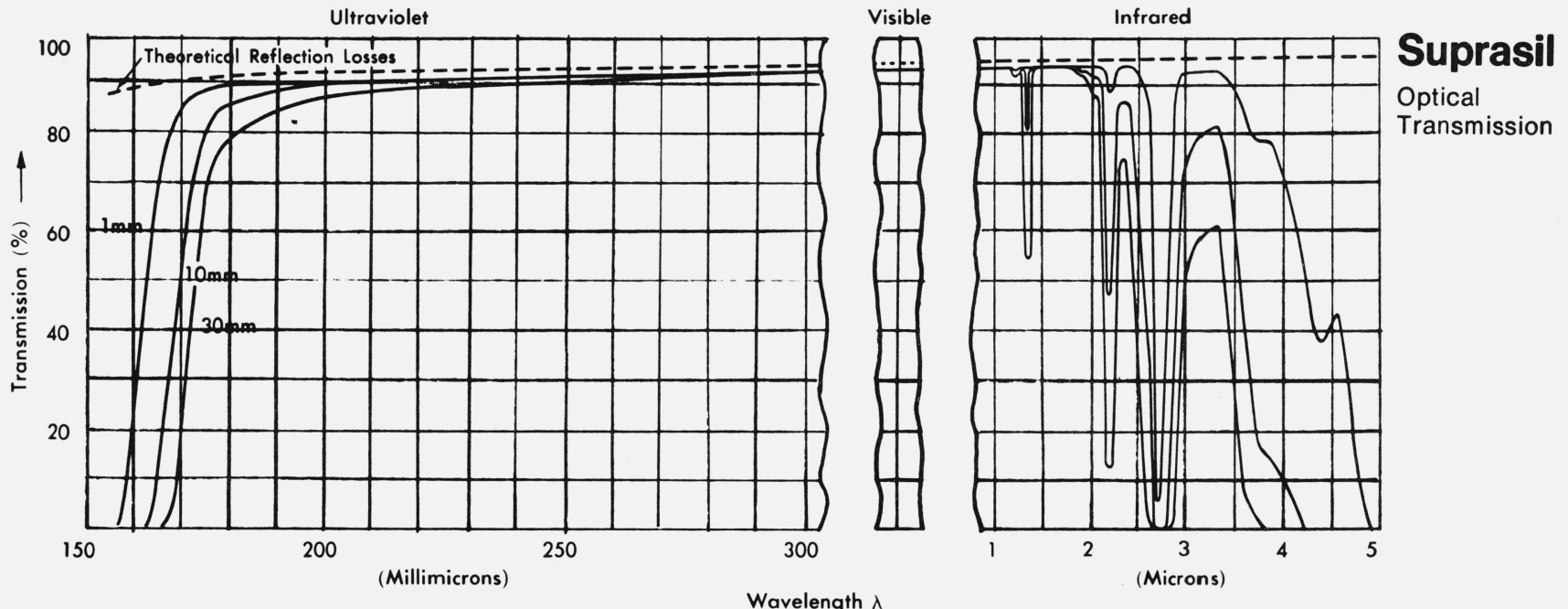

FIGURE 1. Transmission spectra for Suprasil 2 (reproduced with the permission of Amersil,Inc., from F used Quartz and Fused Silica, Optics Bulletin EM-9227).

TABLE 1. Data for preliminary experiments with samples of crystalline quartz and fused silica glass

\begin{tabular}{|c|c|c|c|c|c|c|c|c|c|}
\hline \multirow{2}{*}{$\begin{array}{c}\text { Expt. } \\
\text { No. }\end{array}$} & \multirow{2}{*}{$\begin{array}{l}\text { Stirring } \\
\text { rate }\end{array}$} & \multirow{2}{*}{$\begin{array}{c}\text { Reaction } \\
\text { temp. }\end{array}$} & \multirow{2}{*}{$\begin{array}{l}\text { Duration } \\
\text { of reaction }\end{array}$} & \multirow{2}{*}{$\begin{array}{l}\text { HF Soln. } \\
\text { Mass }\end{array}$} & \multirow{2}{*}{ HF conc. } & \multicolumn{3}{|c|}{ Amounts of reactants } & \multirow{2}{*}{$\begin{array}{l}\text { Mole ratio } \\
\mathrm{HF}: \mathrm{SiO}_{2}\end{array}$} \\
\hline & & & & & & $\mathrm{HF}$ & $\mathrm{H}_{2} \mathrm{O}$ & $\mathrm{SiO}_{2}$ & \\
\hline & rpm & $K$ & $\min$ & $g$ & $w t \%$ & mol & mol & mol & \\
\hline \multicolumn{10}{|c|}{ I: Norwegian natural crystalline quartz (elutriated) } \\
\hline 89 & 550 & 358 & 50 & 323.94 & 22.53 & 3.64 & 13.92 & 0.025840 & 141 \\
\hline \multicolumn{10}{|c|}{ II : Norwegian natural crystalline quartz (passed \#200 sieve) } \\
\hline $\begin{array}{l}97 \\
98 \\
99\end{array}$ & $\begin{array}{l}550 \\
550 \\
550\end{array}$ & $\begin{array}{l}353 \\
353 \\
353\end{array}$ & $\begin{array}{r}100 \\
110 \\
90\end{array}$ & $\begin{array}{l}323.11 \\
322.19 \\
306.78\end{array}$ & $\begin{array}{l}22.53 \\
22.18 \\
22.75\end{array}$ & $\begin{array}{l}3.64 \\
3.57 \\
3.48\end{array}$ & $\begin{array}{l}13.88 \\
13.90 \\
13.14\end{array}$ & $\begin{array}{l}.025872 \\
.025068 \\
.025022\end{array}$ & $\begin{array}{l}141 \\
142 \\
139\end{array}$ \\
\hline \multicolumn{10}{|c|}{ III : Quebec natural crystalline quartz (elutriated) } \\
\hline $\begin{array}{l}100 \\
101 \\
103 \\
105 \\
110\end{array}$ & $\begin{array}{l}550 \\
550 \\
550 \\
550 \\
450\end{array}$ & $\begin{array}{l}353 \\
353 \\
353 \\
353 \\
353\end{array}$ & $\begin{array}{l}45 \\
70 \\
60 \\
60 \\
60\end{array}$ & $\begin{array}{l}319.17 \\
322.22 \\
311.99 \\
316.95 \\
317.89\end{array}$ & $\begin{array}{l}22.75 \\
22.75 \\
22.75 \\
22.75 \\
22.21\end{array}$ & $\begin{array}{l}3.62 \\
3.66 \\
3.54 \\
3.60 \\
3.52\end{array}$ & $\begin{array}{l}13.67 \\
13.80 \\
13.36 \\
13.58 \\
13.71\end{array}$ & $\begin{array}{l}.025312 \\
.029548 \\
.027322 \\
.025431 \\
.026429\end{array}$ & $\begin{array}{l}143 \\
124 \\
130 \\
142 \\
133\end{array}$ \\
\hline \multicolumn{10}{|c|}{ IV : Quebec natural crystalline quartz (passed \#200 sieve) } \\
\hline $\begin{array}{l}108 \\
109\end{array}$ & $\begin{array}{l}450 \\
450\end{array}$ & $\begin{array}{l}353 \\
353\end{array}$ & $\begin{array}{l}120 \\
120\end{array}$ & $\begin{array}{l}327.11 \\
319.89\end{array}$ & $\begin{array}{l}22.21 \\
22.21\end{array}$ & $\begin{array}{l}3.63 \\
3.55\end{array}$ & $\begin{array}{l}14.11 \\
13.80\end{array}$ & $\begin{array}{l}.025869 \\
.025284\end{array}$ & $\begin{array}{l}140 \\
140\end{array}$ \\
\hline \multicolumn{10}{|c|}{ V : Suprasil 2, fused silica glass (elutriated) } \\
\hline $\begin{array}{l}111 \\
113 \\
114 \\
115\end{array}$ & $\begin{array}{l}450 \\
450 \\
450 \\
450\end{array}$ & $\begin{array}{c}353 \\
353 \\
353 \\
-\end{array}$ & $\begin{array}{l}40 \\
30 \\
30 \\
40\end{array}$ & $\begin{array}{l}321.97 \\
323.62 \\
324.03 \\
310.26\end{array}$ & $\begin{array}{l}22.64 \\
22.64 \\
22.64 \\
22.64\end{array}$ & $\begin{array}{l}3.64 \\
3.66 \\
3.66 \\
3.51\end{array}$ & $\begin{array}{l}13.81 \\
13.88 \\
13.90 \\
13.31\end{array}$ & $\begin{array}{l}.024867 \\
.025383 \\
.026096 \\
.024171\end{array}$ & $\begin{array}{l}146 \\
144 \\
140 \\
145\end{array}$ \\
\hline \multicolumn{10}{|c|}{ VI: Suprasil 2, fused silica glass (passed \#200 sieve) } \\
\hline $\begin{array}{l}112 \\
117\end{array}$ & $\begin{array}{l}450 \\
450\end{array}$ & $\begin{array}{l}353 \\
353\end{array}$ & $\begin{array}{l}40 \\
40\end{array}$ & $\begin{array}{l}316.45 \\
331.48\end{array}$ & $\begin{array}{l}22.64 \\
22.64\end{array}$ & $\begin{array}{l}3.58 \\
3.75\end{array}$ & $\begin{array}{l}13.58 \\
14.22\end{array}$ & $\begin{array}{l}.026174 \\
.024628\end{array}$ & $\begin{array}{l}137 \\
152\end{array}$ \\
\hline
\end{tabular}


The crushing and purification of the three samples was essentially the same as described in section 2 for SRM 1654 except that all of the portion passing a \#200 sieve was used. These materials were heated to approximately $320 \mathrm{~K}$ in a similar $1: 1$ aqueous $\mathrm{HCl}$ solution. After the mixture had been stirred vigorously, it was allowed to settle for $5 \mathrm{~min}$ before decanting the liquid which still contained suspended materials. This supernatant liquid was allowed to settle for 30 min more before again decanting. The portion of the sample remaining after the first decantation is called that which "passed \#200 sieve," and that remaining after the second decantation is called "elutriated." The materials were then washed with distilled water as described in section 2. The finest particles were removed during washing and were not recovered.

Information about stirring rates, reaction temperatures, amounts of materials and duration of reaction for the experiments in which the above samples were dissolved in $22-23$ percent $\mathrm{HF}$ solutions at about $350 \mathrm{~K}$ is given in table 1. The Expt. No. is the serial number for experiments in the adiabatic solution calorimeter. It can be seen that the "elutriated" crystalline samples dissolved in approximately $60 \mathrm{~min}$, but those which "passed \#200 sieve" in most cases required nearly twice as long. Reducing the stirring rate from 550 to $450 \mathrm{rpm}$ apparently had little effect on the duration of the reaction, but probably improved the reproducibility of the stirring energy. There appears to be little difference in the duration of reaction for samples of different particle size in the fused silica glass, the time being about half that for the elutriated crystalline samples.

It is apparent from the time required for reaction of these elutriated crystalline materials at $350 \mathrm{~K}$ that the particle sizes are considerably larger than those used by most earlier workers who used isoperibol calorimeters where the duration of the reactions had to be limited to around $30 \mathrm{~min}$. For example, Mulert's sample dissolved at room temperature $\left(18^{\circ} \mathrm{C}\right)$ in 20 peicent $\mathrm{HF}$ in $30 \mathrm{~min} \mathrm{[4];} \mathrm{and} \mathrm{Wietzel's,} \mathrm{also} \mathrm{at}$ room temperature in 35 percent $\mathrm{HF}$, in $15 \mathrm{~min}$ [5]. Most later workers used higher reaction temperatures to avoid the use of such extremely fine particles; however, Jeffes et al. [6], and Stevens and Turkdogan [7] used 18.7 percent $\mathrm{HF}$ at $25^{\circ} \mathrm{C}$. Also, Hummel and Schwiete [8] used 10 percent $\mathrm{HF}$ at $26.5^{\circ} \mathrm{C}$, and the particle size of their sample was reported to be between 2.5 and $5 \mu \mathrm{m}$.

In table 2 are the calorimetric data for the solution of the six samples of $\mathrm{SiO}_{2}$ in aqueous $\mathrm{HF}$ corresponding to the experiments in table 1 . The calorimeter temperatures in all of these experiments were measured with the $25-\Omega$ platinum resistance thermometer. The electrical energy equivalents of the initial and final systems are given. In the stirring energy corrections for the reactions, the uncertainty is estimated to be about 5 percent or less. The methods of calculating the electrical energy equivalents and the corrected temperature rise, $\Delta R_{C}$, reaction, were described previously [3]. The enthalpy of solution, $\Delta H(T)$, at the temperaof reaction which is the mean temperature of reaction,
$T$ reaction, is the product of the mean electrical energy equivalent and the corrected temperature rise divided by the sample mass. The factors as given in section 5 , $1.586 \mathrm{~J} \cdot \mathrm{g}^{-1} \cdot \mathrm{K}^{-1}$ and $1.326 \mathrm{~J} \cdot \mathrm{g}^{-1}(\mathrm{wt} \% \mathrm{HF})^{-1}$, were used for the corrections to $353.15 \mathrm{~K}$ and 24.4 percent $\mathrm{HF}$ to obtain the enthalpy of solution under the conditions of the certified value given in section 5 .

From the mean enthalpies of solution in table 2 we obtain the following differences between the "elutriated" materials and those which "passed \#200 sieve": Norwegian crystal, $115 \mathrm{cal} \cdot \mathrm{mol}^{-1}$; Quebec crystal, $54 \mathrm{cal} \cdot \mathrm{mol}^{-1}$; and Suprasil 2 glass, $60 \mathrm{cal} \cdot$ $\mathrm{mol}^{-1}$. This is an average of about $80 \mathrm{cal} \cdot \mathrm{mol}^{-1}$ and the estimated uncertainty ${ }^{7}$ is of the same magnitude. It then seems reasonable to assume that an error of a hundred $\mathrm{cal} \cdot \mathrm{mol}^{-1}$ or more might be expected when samples composed of extremely fine particles are used.

The mean enthalpies of solution in table 2 also serve for comparison of the values obtained from different samples of natural quartz which passed \# 200 sieve (in kcal · $\mathrm{mol}^{-1}$ ): Norwegian, 33.80; Quebec, 33.86, and Brazilian, 33.92 (see sec. 5). The latter sample did not contain particles which passed \#400 sieve. The three values agree within the experimental uncertainties, $0.10 \mathrm{kcal} \cdot \mathrm{mol}^{-1}$ for the first two and $0.02 \mathrm{kcal} \cdot \mathrm{mol}^{-1}$ for the third. ${ }^{7}$

The enthalpy difference between quartz and $\mathrm{SiO}_{2}$ glass from the elutriated samples is $2.318 \mathrm{kcal} \cdot \mathrm{mol}^{-1}$, and from those which passed \#200 sieve, $2.343 \mathrm{kcal} \cdot$ $\mathrm{mol}^{-1}$; the average of these two values is $2.330 \mathrm{kcal}$. $\mathrm{mol}^{-1}$ (or $162.2 \mathrm{~J} \cdot \mathrm{g}^{-1}$ ). The estimated uncertainty is about $\pm 0.070 \mathrm{kcal} \cdot \mathrm{mol}^{-1}$ (or $4.9 \mathrm{~J} \cdot \mathrm{g}^{-1}$ ). These values agree within the uncertainties with the values of $2.15 \pm 0.15 \mathrm{kcal} \cdot \mathrm{mol}^{-1}$ determined by Holm, Kleppa and Westrum [9]; $2.27 \pm 0.20 \mathrm{kcal} \cdot \mathrm{mol}^{-1}$, by Hummel and Schwiete [8]; $2.21 \pm 0.18 \mathrm{kcal} \cdot \mathrm{mol}^{-1}$, by Mulert [4]; $2.32 \pm 0.06 \mathrm{kcal} \cdot \mathrm{mol}^{-1}$, by Wietzel [5]; and $2.28 \pm 0.02 \mathrm{kcal} \cdot \mathrm{mol}^{-1}$, by Waldbaum [10].

\section{Enthalpy of Solution of SRM 1654 in HF(aq)}

The experiments reported in this section were completed between May and September 1970. The samples used for measurements of the enthalpies of solution ranged from 1.47 to $1.52 \mathrm{~g}$, and the sample holder was filled in the room atmosphere.

The results of 22 experiments given in table 3 were used to obtain by a least squares regression analysis the following linear equation for the enthalpy of solution of quartz in 24.4 percent $\mathrm{HF}$ from $298 \mathrm{~K}$ to $358 \mathrm{~K}$ (in $\mathrm{J} \cdot \mathrm{g}^{-1}$ ):

$$
-\Delta H_{\text {soln }}(T)=2275.0+1.586(T-298.15)
$$

\footnotetext{
${ }^{7}$ The uncertainties (based on $\mathrm{sdm}= \pm 24 \mathrm{cal} \cdot \mathrm{mol}^{-1}$ for the mean enthalpy values in table 2) were based on an analysis of variance by H. H. Ku, Statistical Engineering Laboratory, Institute for Basic Standards.
} 
TABLE 2. Calorimetric data for the preliminary measurements of the enthalpy of solution of various samples of $\mathrm{S}_{\mathrm{iO}}{ }_{2}$, crystal and glass, in aqueous $H F$

\begin{tabular}{|c|c|c|c|c|c|c|c|c|c|c|c|c|}
\hline \multirow{3}{*}{$\begin{array}{l}\text { Expt. } \\
\text { No. }\end{array}$} & \multicolumn{2}{|c|}{ Electrical energy equivalents } & \multirow{2}{*}{$\begin{array}{c}\text { React. } \\
\text { Stirring } \\
\text { Correction }\end{array}$} & \multirow{2}{*}{$\Delta R c_{\text {reaction }}$} & \multirow{2}{*}{$\bar{T}$ reaction } & \multirow{2}{*}{$\begin{array}{c}\text { Sample } \\
\text { Mass }\end{array}$} & \multirow{2}{*}{$-\Delta H(T)^{\mathrm{a}}$} & \multirow{2}{*}{$\begin{array}{c}\text { Corr. to } \\
24.4 \% \mathrm{HF}\end{array}$} & \multirow{2}{*}{$\begin{array}{l}\text { Corr. to } \\
353.15 \mathrm{~K}\end{array}$} & \multirow{2}{*}{\multicolumn{2}{|c|}{$\begin{array}{c}-\Delta H(353.15 \mathrm{~K}) \\
\text { in } 24.4 \% \mathrm{HF}\end{array}$}} & \multirow{2}{*}{ Mean } \\
\hline & Initial & Final & & & & & & & & & & \\
\hline & $J \cdot \Omega^{-1}$ & $J \cdot \Omega^{-1}$ & $\Omega$ & $\Omega$ & K & $g$ & $J \cdot g^{-1}$ & $J \cdot g^{-1}$ & $J \cdot g^{-1}$ & $J \cdot g^{-1}$ & $\mathrm{kcal} \cdot \mathrm{mol}^{-1}$ & $\mathrm{kcal} \cdot \mathrm{mol}^{-1}$ \\
\hline
\end{tabular}

I: Norwegian natural crystalline quartz (elutriated)
89
$16,998.4$
\begin{tabular}{l|l}
$17,031.9$ & 0.00278
\end{tabular}
0.21602
358.324

II: Norwegian natural crystalline quartz (passed \#200 sieve)

\begin{tabular}{l|l|l|l|l|l|l|l|l|l|l|l|l|}
97 & $16,850.7$ & $16,884.3$ & .00477 & .21636 & 353.179 & 1.55451 & 2347.5 & -2.4 & 0.0 & 2349.9 & 33.746 & \\
98 & $16,871.0$ & $16,911.0$ & .00456 & .20982 & 353.185 & 1.50622 & 2352.5 & -2.8 & 0.1 & 2355.2 & 33.822 & 33.795 \\
99 & $16,332.2$ & $16,374.0$ & .00475 & .21633 & 353.203 & 1.50344 & 2352.9 & -2.1 & 0.1 & 2354.9 & 33.818 &
\end{tabular}

III: Quebec natural crystalline quartz (elutriated)

\begin{tabular}{|c|c|c|c|c|c|c|c|c|c|c|c|c|}
\hline 100 & $16,769.5$ & $16,807.5$ & .00179 & .21301 & 353.172 & 1.52087 & 2351.2 & -2.1 & 0.0 & 2353.3 & 33.795 & \\
\hline 101 & $16,831.6$ & $16,876.7$ & .00270 & .24885 & 353.318 & 1.77537 & 2362.3 & -2.1 & 0.3 & 2364.1 & 33.950 & \\
\hline 103 & $16,461.4$ & $16,493.5$ & .00313 & .23541 & 353.251 & 1.64165 & 2362.7 & -2.1 & 0.2 & 2364.6 & 33.957 & 33.909 \\
\hline 105 & $16,635.5$ & $16,674.5$ & .00249 & .21658 & 353.152 & 1.52803 & 2360.4 & -2.1 & 0.0 & 2362.5 & 33.927 & \\
\hline 110 & $16,753.9$ & $16,786.6$ & .00265 & .22337 & 353.084 & 1.58798 & 2358.8 & -2.7 & -0.1 & 2361.6 & 33.914 & \\
\hline
\end{tabular}

$\stackrel{N}{\stackrel{N}{0}}$

IV: Quebec natural crystalline quartz (passed \#200 sieve)

\begin{tabular}{c|c|c}
108 & $17,127.1$ & $16-1$ \\
109 & $16,828.2$ & $16,861.6$
\end{tabular} \mid

.00546

.21356

\begin{tabular}{l|l}
353.176 & 1.55433 \\
353.035 & 1.51917
\end{tabular}

1.51917

2353.0

2356.4

$\left|\begin{array}{l|}-2.7 \\ -2.7\end{array}\right|$

\begin{tabular}{r|}
0.0 \\
-0.2
\end{tabular}

2355.7
2259.3

33.829

33.881

33.855

\begin{tabular}{l|l|l|l|}
111 & $16,961.3$ & $16,990.4$ & .00205 \\
113 & $16,962.7$ & $17,006.0$ & .00178 \\
114 & $16,956.6$ & $16,995.6$ & .00186 \\
115 & $16,440.8$ & $16,489.2$ & .00259
\end{tabular}

\begin{tabular}{l|l|l|l}
.22172 & 353.074 & 1.49414 & 2518.9 \\
.22638 & 353.132 & 1.52513 & 2520.9 \\
.23282 & 353.199 & 1.56800 & 2520.5 \\
.22245 & 353.051 & 1.45230 & 2521.8
\end{tabular}

-2.2
-2.2
-2.2
-2.2

\begin{tabular}{r|}
-0.1 \\
0.0 \\
0.1 \\
-0.2
\end{tabular}

2521.2
2523.1
2522.6
2524.2 36.206
36.233

36.226
36.249

VI: Suprasil 2, fused silica glass (passed \#200 sieve)

\begin{tabular}{|c|c|c|c|c|c|c|c|c|c|c|c|c|}
\hline $\begin{array}{l}112 \\
117\end{array}$ & $\begin{array}{l}16,738.2 \\
17,212.1\end{array}$ & $\begin{array}{l}16,776.0 \\
17,243.1\end{array}$ & $\begin{array}{l}.00207 \\
.00244\end{array}$ & $\begin{array}{l}.23601 \\
.21632\end{array}$ & $\begin{array}{l}353.142 \\
353.154\end{array}$ & $\begin{array}{l}1.57263 \\
1.47980\end{array}$ & $\begin{array}{l}2514.6 \\
2518.2\end{array}$ & $\begin{array}{l}-2.2 \\
-2.2\end{array}$ & $\begin{array}{l}0.0 \\
0.1\end{array}$ & $\begin{array}{l}2516.8 \\
2520.3\end{array}$ & $\begin{array}{l}36.143 \\
36.193\end{array}$ & 36.168 \\
\hline
\end{tabular}

${ }^{a}$ The energy for opening the sample holder, $0.24 \mathrm{~J}$, was subtracted in each experiment. This was measured in seven experiments and the average was $0.24 \pm 0.32(2 \mathrm{sdm}) \mathrm{J}$. 


\begin{tabular}{|c|c|c|c|c|c|c|c|c|}
\hline \multirow{3}{*}{$\begin{array}{c}\text { Expt. } \\
\text { No. }\end{array}$} & \multirow{3}{*}{$\begin{array}{c}\begin{array}{c}\text { Sample } \\
\text { mass }\end{array} \\
g\end{array}$} & \multicolumn{2}{|c|}{ Electrical energy equivalents } & \multirow{3}{*}{$\begin{array}{c}\text { Corrected } \\
\begin{array}{c}\text { temperature } \\
\text { rise }\end{array} \\
K\end{array}$} & \multirow{3}{*}{$\begin{array}{c}\bar{Q}_{\text {reaction }} \\
J\end{array}$} & \multirow{2}{*}{\multicolumn{2}{|c|}{$\bar{T}$ reaction }} & \multirow{3}{*}{$\frac{-\Delta H_{\text {soln }}(T)}{J \cdot g^{-1}}$} \\
\hline & & \multirow{2}{*}{$\begin{array}{l}\text { Initial } \\
J \cdot K^{-1}\end{array}$} & \multirow{2}{*}{$\frac{\text { Final }}{J \cdot K^{-1}}$} & & & & & \\
\hline & & & & & & $K$ & ${ }^{\circ} \mathrm{C}$ & \\
\hline $432^{a}$ & 1.48772 & 1586.0 & 1590.0 & 2.13480 & 3390.0 & 298.898 & 25.748 & 2278.7 \\
\hline 437 & 1.50235 & 1582.0 & 1585.8 & 2.15908 & 3419.8 & 298.226 & 25.076 & 2276.3 \\
\hline 439 & 1.48326 & 1596.6 & 1600.3 & 2.12282 & 3393.2 & 308.348 & 35.198 & 2287.7 \\
\hline $440^{b}$ & 1.47684 & 1582.0 & 1586.8 & 2.11975 & 3358.5 & 298.117 & 24.967 & 2274.1 \\
\hline 463 & 1.50842 & 1617.8 & 1624.2 & 2.15912 & 3499.9 & 323.676 & 50.616 & 2320.2 \\
\hline 464 & 1.49148 & 1648.2 & 1651.4 & 2.13083 & 3515.4 & 349.026 & 75.876 & 2357.0 \\
\hline 465 & 1.50061 & 1648.6 & 1650.3 & 2.13642 & 3523.9 & 348.406 & 75.256 & 2348.3 \\
\hline $466^{b}$ & 1.50612 & 1653.1 & 1654.7 & 2.15058 & 3556.8 & 352.721 & 79.571 & 2361.6 \\
\hline 467 & 1.49116 & 1653.9 & 1656.6 & 2.12867 & 3523.5 & 353.153 & 80.003 & 2362.9 \\
\hline $468^{a}$ & 1.49085 & 1653.5 & 1656.0 & 2.12805 & 3521.4 & 352.935 & 79.785 & 2362.0 \\
\hline $469^{b}$ & 1.49814 & 1653.2 & 1656.5 & 2.13888 & 3539.5 & 352.985 & 79.835 & 2362.6 \\
\hline 470 & 1.51161 & 1653.6 & 1655.8 & 2.15700 & 3569.2 & 352.983 & 79.833 & 2361.2 \\
\hline 471 & 1.49410 & 1653.4 & 1655.8 & 2.13301 & 3529.3 & 353.172 & 80.022 & 2362.1 \\
\hline \multirow[t]{2}{*}{473} & 1.50839 & 1653.6 & 1655.9 & 2.15420 & 3564.7 & 353.217 & 80.067 & 2363.2 \\
\hline & & $J \cdot \Omega^{-1}$ & $J \cdot \Omega^{-1}$ & $\Omega$ & & & & \\
\hline 480 & 1.51163 & 16,557 & 16,602 & 0.215304 & 3569.6 & 352.883 & 79.733 & 2361.4 \\
\hline 481 & 1.51260 & 16,560 . & 16,603 & .215479 & 3573.0 & 352.872 & 79.722 & 2362.2 \\
\hline 482 & 1.51806 & $16,571$. & 16,611 & .216067 & 3584.8 & 352.888 & 79.738 & 2361.4 \\
\hline 483 & 1.49911 & 16,570 . & 16,611 & .213384 & 3540.1 & 352.865 & 79.715 & 2361.5 \\
\hline 484 & 1.50632 & $16,568$. & 16,609 & .214454 & 3557.5 & 352.892 & 79.742 & 2361.7 \\
\hline 485 & 1.50231 & 16,489 . & 16,531 & .214070 & 3534.3 & 347.857 & 74.707 & 2352.6 \\
\hline 486 & 1.51417 & $16,658$. & 16,698 & .215352 & 3591.6 & 357.910 & 84.760 & 2372.0 \\
\hline 487 & 1.51144 & 16,659 . & 16,700 & .214945 & 3585.2 & 357.894 & 84.744 & 2372.1 \\
\hline
\end{tabular}

${ }^{a}$ Particle size of sample: Passed \#100 and retained on \#200 sieve; finest particles removed in washing.

${ }^{b}$ Particle size of sample: Passed \#400 sieve; finest particles removed in washing.

where $T$ is the isothermal reaction temperature in kelvins, the standard error of the estimate is \pm 2.4 $\mathrm{J} \cdot \mathrm{g}^{-1}$, the standard error of the constant term is $\pm 1.2 \mathrm{~J} \cdot \mathrm{g}^{-1}$, and the standard error of the slope is $\pm 0.025 \mathrm{~J} \cdot \mathrm{g}^{-1} \cdot \mathrm{K}^{-1}$. The uncertainty is probably greater at the low temperatures than at the high temperatures because of the longer reaction periods. The average $\Delta C p=-1.586 \pm 0.025 \mathrm{~J} \cdot \mathrm{g}^{-1} \cdot \mathrm{K}^{-1}$.

In the tables, the experiment number is the serial number of the experiment in the adiabatic solution calorimeter; omitted numbers are experiments on other compounds, other test reactions, or thermometer calibrations. The electrical energ y equivalents (EEE) of the initial and final systems are given in $\mathrm{J} \cdot \mathrm{K}^{-1}$ where the quartz-oscillator thermometer was used, and in $\mathrm{J} \cdot \Omega^{-1}$ where the $25-\Omega$ platinum resistance thermometer ${ }^{8}$ was used. The heat evolved during the reaction, in joules, is $\left.Q_{\text {reaction }}=\left[\mathrm{EEE}_{i}+\mathrm{EEE}_{f}\right) / 2\right](\Delta T) . \bar{T}$ reaction is the mean temperature of the reaction. The isothermal enthalpy at the temperature of reaction is equal to the enthalpy at the mean temperature of reaction, or $\Delta H(T)=\Delta H(\bar{T})^{9}$. The corrections to obtain $\Delta H$ at $353.15 \mathrm{~K}$ were made using $\Delta C p=-1.586$ $\mathrm{J} \cdot \mathrm{g}^{-1} \cdot \mathrm{K}^{-1}$ or $-95.3 \mathrm{~J} \cdot \mathrm{mol}^{-1} \cdot \mathrm{K}^{-1}$.

Figure 2 is a plot on a molar basis of the enthalpies of solution versus the temperatures of reaction given in table 3 (differences from $298.15 \mathrm{~K}$ and the corre-

\footnotetext{
${ }^{8}$ On this thermometer one kelvin is $0.10104 \Omega$ at $298.15 \mathrm{~K}$ and $0.09939 \Omega$ at $353 \mathrm{~K}$. (See [3] for thermometer calibration data.)

${ }_{9}^{9}$ The use of only $\mathrm{EEE}_{i}$ would give $\Delta H$ at the final temperature, and $\mathrm{EEE}_{f}$ would give $\Delta H$ at the initial temperature, and the use of $\left(\mathrm{EEE}_{i}+\mathrm{EEE}_{f}\right) / 2$ gives $\Delta H$ at $\bar{T}$.
}

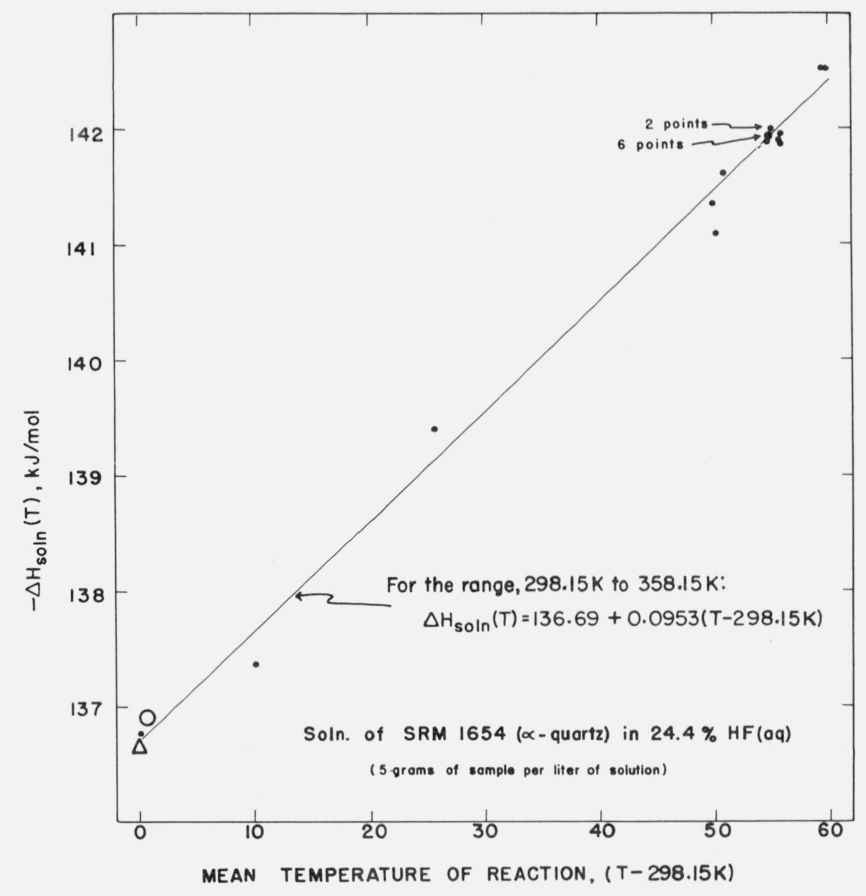

FIGURE 2. A plot of the data in table 3 showing the relationships of enthalpy of solution of quartz in 24.4 percent $\mathrm{HF}(a q)$ to the mean temperature of reaction.

sponding equation are given). Five of the points were measurements on samples of different particle size 
than SRM 1654 (37 to $74 \mu \mathrm{m}$ ); the sample 74 to $149 \mu \mathrm{m}$, was used for the point in the circle and one of those in the cluster of 6 near $(T-298.15 \mathrm{~K})=55 \mathrm{~K}$, and the sample which was less than $37 \mu \mathrm{m}$ was used for the point in the triangle and 2 points in the group just below $(T-298.15 \mathrm{~K})=55 \mathrm{~K}$. Thus, there appears to be no difference in the results obtained with various particle sizes in this range. The ultrafine material was removed from all three portions of the quartz during the washing. Therefore, since no significant difference was detected in the enthalpies of solution of the three portions, it may be concluded that no change in the enthalpy of solution of the SRM 1654 will result from particle separation within the sample and that surface energy effects are negligible in this sample (which has the ultrafine material removed).

In Expt. No. 490 (not included in the tables or equations), the sample of smallest particle size $(<37 \mu \mathrm{m})$ was dissolved in 24.31 percent $\mathrm{HF}$ and $\Delta H(352.912$ $\mathrm{K})=-2361.1 \mathrm{~J} \cdot \mathrm{g}^{-1}$ which agreed with similar-experiments in table 3 . In addition three electrical calibrations of the initial system and three of the final system were measured and the following results were obtained:

\begin{tabular}{c|c|c|c}
\hline \hline \multicolumn{2}{c|}{ Initial system } & \multicolumn{2}{c}{ Final system } \\
\hline $\bar{T}, \mathrm{~K}$ & $\mathrm{EEE}, \mathrm{J} \cdot \Omega^{-1}$ & $\bar{T}, \mathrm{~K}$ & $\mathrm{EEE}, \mathrm{J} \cdot \Omega^{-1}$ \\
\hline 346.383 & 16,493 & 355.072 & 16,610 \\
348.570 & 16,532 & 357.252 & 16,647 \\
350.755 & 16,568 & 359.428 & 16,684 \\
\hline
\end{tabular}

These values confirmed the linearity of the energy equivalents (EEE) in this temperature range, and since $d(\mathrm{EEE}) / d T$ was the same for the initial and final systems, only one initial and one final calibration was necessary in each experiment.

Two experiments were not included in the tables because low values were obtained and leakage of the sample holder was suspected (this sometimes occurred when sample particles were spilled accidentally on the polytetrafluoroethylene o-ring when filling the sample holder). These were Expt. No. 433 in 24.4 percent HF, $-\Delta H(298.730 \mathrm{~K})=2261 . \mathrm{J} \cdot \mathrm{g}^{-1}$; and Expt. No. 488 in 29.84 percent $\mathrm{HF},-\Delta H(352.95 \mathrm{~K})=2367$. $\mathrm{J} \cdot \mathrm{g}^{-1}$. Expts. No. 435, 436, and 438 were not used because the stirrer was turned off during the reaction period in an effort to reduce the total stirring energy, however, the resultant uncertainties proved to be larger than expected. Expts. No. 472, 474, and 478 were lost because of electronic problems. Expts. No. 441 through 462 and 492 through 499 were measurements on other reactions.

The results of experiments given in table 4 show the effect of varying concentrations of aqueous hydrofluoric acid on the enthalpy of solution of SRM 1654 at $353 \mathrm{~K}$. A least squares fit of these data gives the following equation for the range of 18 to 30 percent $\mathrm{HF}$ (in $J \cdot g^{-1}$ ):

$-\Delta H_{\text {soln }}(353.15 \mathrm{~K})=2362.10+1.429(\mathrm{wt} \% \mathrm{HF}-24.40)$

$$
+0.069(\mathrm{wt} \% \mathrm{HF}-24.40)^{2} .
$$

The standard error of the constant term is \pm 0.73 $\mathrm{J} \cdot \mathrm{g}^{-1}$, of the linear term, $\pm 0.118 \mathrm{~J} \cdot \mathrm{g}^{-1}$, and of the quadratic term, $\pm 0.028 \mathrm{~J} \cdot \mathrm{g}^{-1}$. The standard error of the estimate is $\pm 1.6 \mathrm{~J} \cdot \mathrm{g}^{-1}$. The mean slope is $1.326 \mathrm{~J} \cdot \mathrm{g}^{-1}(\mathrm{wt} \% \mathrm{HF}-24.40)^{-1}$.

Figure 3 is a plot on the molar basis of the enthalpies of solution versus the HF concentration as given in table 4. Although a quadratic equation is barely justified over a linear equation, logically the slope should decrease in the more dilute solutions, although there is greater uncertainty in this region because of

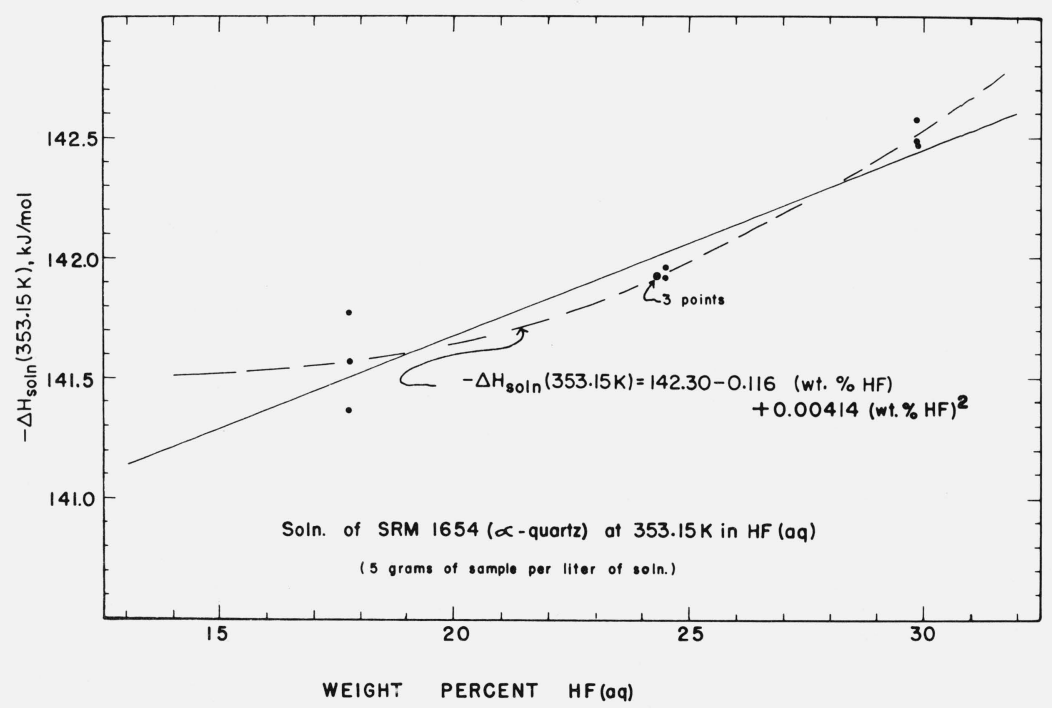

Figure 3. A plot of the data in table 4 showing the relationships of the enthalpy of solution of quartz at $353 \mathrm{~K}$ to the concentration of $\mathrm{HF}(\mathrm{aq})$.

The straight line represents the mean slope, $0.0796 \pm 0.0084 \mathrm{~kJ} \cdot \mathrm{mol}^{-1}(\mathrm{wt} \% \mathrm{HF})^{-1}$. 
TABLE 4. Data for experiments showing the relationship of the enthalpy of solution of quartz in aqueous $\mathrm{HF}$ at $353.15 \mathrm{~K}$ to the $\mathrm{HF}$ concentration

\begin{tabular}{|c|c|c|c|c|c|c|c|c|c|c|c|}
\hline \multirow{4}{*}{$\begin{array}{c}\begin{array}{c}\text { Expt. } \\
\text { No. }\end{array} \\
\\
\end{array}$} & \multirow{4}{*}{$\begin{array}{c}\begin{array}{c}\text { Sample } \\
\text { mass }\end{array} \\
g \\
1.51008\end{array}$} & \multirow{4}{*}{$\begin{array}{c}\text { Mass HF } \\
\text { soln } \\
g \\
317.66\end{array}$} & \multirow{4}{*}{$\begin{array}{c}\text { Conc. of } \\
\text { HF soln }\end{array}$} & \multicolumn{2}{|c|}{ Elec. energy equiv. } & \multirow{4}{*}{$\begin{array}{c}\begin{array}{c}\text { Corrected } \\
\text { temperature } \\
\text { rise }\end{array} \\
\Omega \\
0.208932\end{array}$} & \multirow{4}{*}{$\begin{array}{c}Q \text { reaction } \\
J \\
3555.8\end{array}$} & \multirow{2}{*}{\multicolumn{2}{|c|}{$\bar{T}$ reaction }} & \multirow{4}{*}{$\begin{array}{c}\begin{array}{c}\text { Corr. } \\
\text { to } \\
353.15 \mathrm{~K}\end{array} \\
J \cdot g^{-1} \\
-0.5\end{array}$} & \multirow{4}{*}{$\begin{array}{c}\underset{(353.15 \mathrm{~K} \text { K })}{-\Delta H_{\text {sin }}} \\
J \cdot g^{-1} \\
2355.2\end{array}$} \\
\hline & & & & \multirow{3}{*}{\multicolumn{2}{|c|}{\begin{tabular}{c|c} 
Initial & Final \\
\multicolumn{3}{|c}{$J \cdot \Omega^{-1}$} \\
$17,003 \quad 17,035$
\end{tabular}}} & & & & & & \\
\hline & & & & & & & & $K$ & ${ }^{\circ} \mathrm{C}$ & & \\
\hline & & & & & & & & 352.813 & 79.663 & & \\
\hline 480 & 1.51163 & 317.58 & 24.46 & 16,557 & 16,602 & .215304 & 35696 & 352.883 & 79.733 & -.4 & 2361.8 \\
\hline 481 & 1.51260 & 317.63 & 24.46 & $16 ; 561$ & 16,603 & .215479 & 3573.0 & 352.872 & 79.722 & -.4 & 2362.6 \\
\hline 482 & 1.51806 & 317.63 & 24.31 & 16,571 & 16,611 & .216067 & 3584.8 & 352.888 & 79.738 & -.4 & 2361.8 \\
\hline 483 & 1.49911 & 317.64 & 24.31 & 16,570 & 16,611 & .213384 & 3540.1 & 352.865 & 79.715 & -.5 & 2362.0 \\
\hline 484 & 1.50632 & 317.59 & 24.31 & 16,568 & 16,609 & .214454 & 3557.5 & 352.892 & 79.742 & -.4 & 2362.3 \\
\hline 489 & 1.51622 & 317.58 & 17.75 & 17,006 & 17,031 & .210117 & 3575.9 & 352.799 & 79.649 & -.6 & 2359.0 \\
\hline 491 & 1.51067 & 317.53 & 29.84 & 16,230 & 16,283 & .220470 & 3584.1 & 352.922 & 79.772 & -.4 & 2372.9 \\
\hline 500 & 1.48970 & 317.62 & 17.75 & 17,014 & 17,039 & .205834 & 3504.6 & 353.081 & 79.931 & -.1 & 2352.7 \\
\hline 501 & 1.49384 & 317.65 & 29.82 & 16,236 & 16.293 & .217811 & 3542.6 & 353.260 & 80.110 & +.2 & 2371.2 \\
\hline 502 & 1.51193 & 317.55 & 29.82 & 16,234 & 16,286 & .220526 & 3585.8 & 353.260 & 80.110 & +.2 & 2371.4 \\
\hline
\end{tabular}


the longer reaction periods. The mole ratio of $\mathrm{HF}: \mathrm{SiO}_{2}$ in the experiments reported here ranges from 111 (No. 489) to 191 (No. 501). This is not sufficient to establish dilution effects over a large range.

TABLE 5. Results of the experiments on which the certified value for the enthalpy of solution of SRM 1654 is based

\begin{tabular}{c|c|c|c|c}
\hline \hline $\begin{array}{c}\text { Expt. } \\
\text { No. }\end{array}$ & $\begin{array}{c}\text { Concentration } \\
\text { of HF soln }\end{array}$ & $-\Delta H_{\text {soln }}(T)$ & $\begin{array}{c}\text { Correction } \\
\text { to 353.15 K }\end{array}$ & $\begin{array}{c}-\Delta H_{\text {soln }} \\
(353.15 \mathrm{~K})\end{array}$ \\
\hline & $w t \%$ & $J \cdot g^{-1}$ & $J \cdot g^{-1}$ & $J \cdot g^{-1}$ \\
467 & 24.43 & 2362.9 & 0.0 & 2362.9 \\
470 & 24.43 & 2361.2 & -0.3 & 2361.5 \\
471 & 24.46 & 2362.1 & 0.0 & 2362.1 \\
473 & 24.46 & 2363.2 & +0.1 & 2363.1 \\
& & & & \\
480 & 24.46 & 2361.4 & -0.4 & 2361.8 \\
481 & 24.46 & 2362.2 & -0.4 & 2362.6 \\
482 & 24.31 & 2361.4 & -0.4 & 2361.8 \\
483 & 24.31 & 2361.5 & -0.5 & 2362.0 \\
484 & 24.31 & 2361.7 & -0.4 & 2362.1 \\
& & & 2362.2 \\
Mean.... & 24.40 & \multicolumn{4}{l}{} & \pm 0.2 \\
Standard deviation of the mean
\end{tabular}

In table 5 are summarized the results of the nine experiments on which the following certified value for the enthalpy of solution in 24.4 percent $\mathrm{HF}(\mathrm{aq})$ of SRM 1654 ( $\alpha$-quartz) is based:

$$
\Delta H_{\text {soln }}(353.15 \mathrm{~K})=-2362.2 \pm 1.1 \mathrm{~J} \cdot \mathrm{g}^{-1} .
$$

This is for a concentration of $5 \mathrm{~g}$ of sample per 1000 $\mathrm{cm}^{3}$ of $\mathrm{HF}$ solution. The enthalpy value also applies to the enthalpy of solution of pure quartz within the assigned uncertainty. The 0.05 percent $\left(1.1 \mathrm{~J} \cdot \mathrm{g}^{-1}\right)$ uncertainty limit assigned is the square root of the sum of the squares of the following uncertainties: $0.4 \mathrm{~J} \cdot \mathrm{g}^{-1}$ for experimental precision at the 95 percent confidence level; $1.0 \mathrm{~J} \cdot \mathrm{g}^{-1}$ for possible inert material (this is about twice the percentage of inert material found in the analysis); $0.3 \mathrm{~J} \cdot \mathrm{g}^{-1}$ for errors in analysis of $\mathrm{HF}$ stock solutions; and $0.2 \mathrm{~J} \cdot \mathrm{g}^{-1}$ for possible collective errors in values used for calibrations of measuring instruments and reference standards and in heater-lead error. Measurements of the temperature rise in the first four experiments given in table 5 were made with a quartz-oscillator thermometer, and in the last five experiments, with a platinum resistance thermometer.

\section{Discussion of Results}

Prior to this work very little information was available regarding the effects of temperature and $\mathrm{HF}$ concentration on the enthalpy of solution of low quartz. Hummel and Schwiete [8] published plots of their measured values for the enthalpies of solution of quartz versus the temperatures of reaction in 20 percent $\mathrm{HF}$ from about 25 to $80^{\circ} \mathrm{C}$, and versus concentration from 10 to 39 percent $\mathrm{HF}$ solution. The slope of the straight line from their temperature data is nearly the same as that given in figure 2 although their enthalpy values are about 1 percent smaller than our corresponding values. Their plot showing the effect of HF concentration on the enthalpy includes a greater range than in our measurements and their value at 24 percent $\mathrm{HF}$ is only slightly lower than ours corrected to the same temperature. Their value shown in table 6 appears to be about 1 percent lower than other recent measurements of the enthalpy of solution of low quartz.

Some of the other values reported previously for the enthalpy of solution of low quartz in aqueous $\mathrm{HF}$ are listed in table 6; also given are these values corrected to the conditions of the certified value for SRM 1654

TABLE 6. Comparison of some values reported for the enthalpy of solution of low quartz in HF (aq)

\begin{tabular}{|c|c|c|c|c|c|c|}
\hline Reference & Year & $\begin{array}{l}\text { Value reported } \\
\text { for }-\Delta H(T)\end{array}$ & $T$ reaction & $\begin{array}{l}\mathrm{HF} \\
\text { conc. }\end{array}$ & $\begin{array}{l}-\Delta H\left(80^{\circ} \mathrm{C}\right) \\
\text { in } 24.4 \% \mathrm{HF}\end{array}$ & $\begin{array}{c}\text { Corrected value } \\
\text { minus } \\
\text { certified value }\end{array}$ \\
\hline & & $k J \cdot \mathbf{m o l}^{-1}$ & ${ }^{\circ} \mathrm{C}$ & wt $\%$ & $k J \cdot \mathrm{mol}^{-1}$ & $k J \cdot \mathrm{mol}^{-1}$ \\
\hline Mulert [4].. & 1912 & $125.23 \pm 2.51$ & 18 & 20 & 131.48 & -10.45 \\
\hline Wietzel [5]... & 1921 & 140.79 & b 18 & 35 & 145.87 & +3.94 \\
\hline Roth and Troitzsch [11]. & 1932 & $137.78 \pm 0.21$ & 77.2 & 20.6 & $* 140.79$ & -1.15 \\
\hline Troitzsch [12]............ & 1936 & $139.91 \pm 0.08$ & 77 & 20.6 & 140.50 & -1.43 \\
\hline Torgeson and Sahama [13]. & 1948 & $138.07 \pm 0.08$ & 73.7 & 20.1 & $* 141.29$ & -0.64 \\
\hline Sahama and Neuvonen [14]. & 1951 & $139.08 \pm 0.20$ & 75.1 & 20.1 & *142.23 & +0.30 \\
\hline King $[15] \ldots \ldots \ldots \ldots \ldots \ldots \ldots \ldots$ & 1951 & $139.28 \pm 0.33$ & 73.7 & 20.1 & *142.50 & +0.57 \\
\hline & & $137.28 \pm 0.38$ & 50 & 20.1 & ${ }^{*} 141.62$ & -0.31 \\
\hline Kracek, et al. [16].. & 1951 & $139.33 \pm 0.17$ & 74.7 & 20.0 & $* 142.51$ & +0.58 \\
\hline King [17].. & $195 ?$ & $138.62 \pm 0.12$ & 74.7 & 20.0 & $* 141.80$ & -0.13 \\
\hline $\begin{array}{l}\text { King }[17] \ldots \ldots \ldots \ldots \\
\text { Jeffes, et al. [6]... }\end{array}$ & $\begin{array}{l}1952 \\
1954\end{array}$ & $138.36 \pm 0.42$ & 60 & 20.1 & ${ }^{*} 142.23$ & +0.30 \\
\hline $\begin{array}{l}\text { Jeffes, et al. } \\
\text { Stevens and Turkdogan [7]. }\end{array}$ & $\begin{array}{l}1954 \\
1955\end{array}$ & $137.11 \pm 0.79$ & 25 & 18.7 & 142.80 & +0.87 \\
\hline $\begin{array}{l}\text { Stevens and Turkdogan [7]. } \\
\text { Hummel and Schwiete [8].. }\end{array}$ & $\begin{array}{l}1955 \\
1959\end{array}$ & ${ }^{\mathrm{a}} 135.56 \pm 0.46$ & 25 & 18.7 & 141.26 & -0.67 \\
\hline $\begin{array}{l}\text { Hummel and Schwiete }[8] . \\
\text { Waldbaum }[10] \ldots \ldots \ldots \ldots \ldots \ldots . .\end{array}$ & 1959 & $134.85 \pm 0.42$ & 26.5 & 19.5 & 140.33 & -1.60 \\
\hline Waldbaum [10]... & $\begin{array}{l}1970 \\
1971\end{array}$ & $139.00 \pm 0.08$ & $\begin{array}{l}49.7 \\
49.7\end{array}$ & 20.1 & 142.23 & $\begin{array}{l}+0.30 \\
+0.24\end{array}$ \\
\hline This work........ & 1970 & $\begin{array}{l}138.93 \pm 0.40 \\
141.93 \pm 0.07\end{array}$ & 80.0 & $\begin{array}{l}20.1 \\
24.4\end{array}$ & $\begin{array}{l}142.17 \\
141.93\end{array}$ & $\begin{array}{c}+0.24 \\
-\end{array}$ \\
\hline
\end{tabular}

${ }^{*}$ Corrected to the isothermal reaction using $\mathrm{Cp}$ (quartz) obtained from the JANAF tables [18].

${ }^{\mathrm{a}} \mathrm{We}$ have used their value before their correction for a hypothetical amount of amorphous $\mathrm{SiO}_{2}$ since none of the other values have such a correction; their value including the correction is $134.68 \mathrm{~kJ} \cdot \mathrm{mol}^{-1}$ which becomes 140.36 in 24.4 percent $\mathrm{HF}$ at $80^{\circ} \mathrm{C}$.

${ }^{\mathrm{b}}$ Temperature not specified but assumed to be $18^{\circ} \mathrm{C}$. 
using $0.0953 \mathrm{~kJ} \cdot \mathrm{mol}^{-1} \cdot \mathrm{K}^{-1}$ and $0.0796 \mathrm{~kJ} \cdot \mathrm{mol}^{-1}$ $(\mathrm{wt} \% \mathrm{HF})^{-1}$. The corrections may do an injustice to the values for reactions in the lower HF concentrations and near room temperature where our equations are known to have larger uncertainties. However, under those conditions the uncertainty in the measurements must also be large because of the slow reaction rate, and the very finely divided samples which had to be used may have introduced surface energy effects. Except for the value of Hummel and Schwiete, the corrected values are in good agreement for all values reported since 1940.

An adiabatic calorimeter was used in the present work; all other values given in table 6 were measured in isoperibol calorimeters. Waldbaum used a calorimeter previously described by Robie [19]. The values of Troitzsch (1936), Waldbaum, and the present work are for the isothermal reaction where the sample was in a sealed container inside the calorimeter until initiation of the reaction; all other values in table 6 are for the sample at $25^{\circ} \mathrm{C}$ (or room temperature) and the solution and products at the mean temperature of reaction, therefore, in order to convert these to the isothermal reactions corrections were made using Cp of quartz at the mean temperature of the excursions, taken from the JANAF Tables [18]. This correction was not made for the reactions at or near $25^{\circ} \mathrm{C}$.

All values in table 6 except the last three were obtained from samples which had been elutriated or extremely finely powdered in order to complete the solution in a short period of time. Both of Waldbaum's samples passed a \#400 sieve but fine particles were removed by elutriation, and SRM 1654 used in this work was between \#200 and \#400 sieve size with fine particles removed by elutriation. The samples were natural Brazilian quartz in this work and in Waldbaum's. The sample for Waldbaum's 1970 value was from the same quartz fragment which he supplied to Holm and Kleppa [9], and for his 1971 value he used a sample from our portion 3 (see sec. 2) which was the same as SRM 1654 except in particle size. Wietzel's sample was Carrara quartz; Kracek's samples were from Sycamore Island and Lisbon, Maryland, respectively; and all other samples were natural quartz of unstated origin.
The corrected values given in table 6 are in good agreement when the variables of time, calorimeters, samples, and procedures are considered. This would suggest that measurements made with a single, uniform sample such as SRM 1654, can serve as an indication of the relative accuracy and precision of measurements by various calorimeters employed in HF solution cálorimetry.

We acknowledge with gratitude the advice and information relative to the preparation of this paper supplied by David L. Waldbaum of Princeton University.

\section{References}

[1] Frondel, C., The System of Mineralogy, III (John Wiley and Sons, Inc., New York, N.Y., 1962), pp 1 and 117.

[2] Commission on Atomic Weights, Pure and Applied Chem. 21, 91 (1970).

[3] Prosen, E. J., and Kilday, M. V., J. Res. Nat. Bur. Stand. (U.S.), 77A (Phys. and Chem.) No. 2, 179-203 (Mar.-Apr. 1973).

[4] Mulert, O., Z. anorg. Chem. 75, 198 (1912).

[5] Wietzel, R., Z. anorg. allgem. Chem. 1 16,71 (1921).

[6] Jeffes, J. H. E., Richardson, F. D., and Pearson, J., Trans. Faraday Soc. 50, 364 (1954).

[7] Stevens, C. G., and Turkdogan, E. T., Trans. Faraday Soc. 51, 357 (1955).

[8] Hummel, von C., and Schwiete, H. E., Glastechn. Ber. 32, 327 (1959).

[9] Holm, J. L., Kleppa, O. J., and Westrum, E. F., Jr., Geochim. Cosmo. Chim. Acta 31, 2289 (1967).

[10] Waldbaum, D. R., written communication $(1970,1972)$.

[11] Roth, W. A., and Troitzsch, H., Arch. Eisenhüttenw. 6, 79 (1932).

[12] Troitzsch, H., Diss., Technischen Hochschule zu Braunschweig (1936).

[13] Torgeson, D. R., and Sahama, Th. G., J. Am. Chem. Soc. 70, 2156 (1948).

[14] Sahama, Th. G., and Neuvonen, K. J., Bull. Comm. Geol. Finlande 154, 177 (1951).

[15] King, E. G., J. Am. Chem. Soc. 73, 656 (1951).

[16] Kracek, F. C., Neuvonen, K. J., and Burley, G., J. Wash. Acad. Sci. 41,373 (1951).

17] King. E. G., J. Am. Chem. Soc. 74, 4446 (1952).

[18] JANAF Thermochemical Tables, 2nd Edition, D. R. Stull and H. Prophet, Project Directors, Nat. Stand. Ref. Data Ser. Nat. Bur. St and. (U.S.), 37, 1141 pages (June 1971).

[19] Robie, R. A., Rev. Sci. Instr. 36, 484 (1965).

(Paper 77A2-763) 